\title{
Identification of Maintainer and Restorer Lines for WA Cytoplasmic Male Sterility in Rice Using Pollen Fertility and Spikelet Fertility
}

\author{
Vanitha $^{1 *}$, Jayateertha R. Diwan ${ }^{1}$, D. Shreedhara ${ }^{2}$, Vikas V. Kulkarni ${ }^{3}$, \\ K. Mahantashivayogayya ${ }^{2}$ and Vijaykumar N. Ghante ${ }^{3}$ \\ ${ }^{1}$ Department of Genetics and Plant Breeding, University Agricultural Sciences, \\ Raichur-584104, India \\ ${ }^{2}$ Agricultural Research Station, Gangavati, University Agricultural Sciences, \\ Raichur-584104, India \\ ${ }^{3}$ Main Agricultural Research Station, University Agricultural Sciences, Raichur-584104, India \\ *Corresponding author
}

\section{A B S T R A C T}

\begin{tabular}{|c|}
\hline Keywords \\
\hline $\begin{array}{l}\text { Cytoplasmic Male } \\
\text { Sterility, Fully } \\
\text { Maintainer, Hybrid } \\
\text { rice, Partial } \\
\text { Maintainer }\end{array}$ \\
\hline Article Info \\
\hline $\begin{array}{l}\text { Accepted: } \\
28 \text { March } 2020 \\
\text { Available Online: } \\
10 \text { April } 2020\end{array}$ \\
\hline
\end{tabular}

Hybrid technology in many crops has contributed 20-30 per cent increase in the production and exploitation of heterosis through the development of $F_{1}$ hybrids which has been recently deployed in rice with yield advantage of 20-25 per cent over best pure lines. The main aim of any plant breeding programme is to develop special high yielding hybrids and success of any plant breeding programme depends on the choice of appropriate genotypes as parents in the hybridization programme. To accomplish this, the breeding programme can efficiently be planned with prior knowledge of the genetic makeup of parental genotypes whether they are sterile or complete restorer. Eighty-four rice genotypes $\left(\mathrm{F}_{1}\right.$ crosses) were selected for identification of fertility restoration for five CMS lines with WA cytoplasm. $F_{1}$ crosses were analysed for pollen fertility and spikelet fertility and were classified into four classes $\mathrm{viz}$, complete maintainer, partial maintainer, partially restorer and fully restorer. Out of $84 \mathrm{~F}_{1}$ hybrids, 13 lines were completely fertile and 5 completely sterile. The remaining 66 hybrids expressed varying degrees of fertility (both pollen and spikelet). Forty-nine of them were partial maintainers and the remaining seventeen were partial restorers (based on spikelet fertility).

\section{Introduction}

Rice (Oryza sativa L.), a member of family Gramineae $(2 \mathrm{n}=24)$, is the most important food crop of the developing world. It provides upto two-thirds of the calories for quite pair of billion folks in Asia and is also a major source of protein for Asian people. Demand for rice is anticipated to increase by about 3 per cent annually over the next decade and beyond. In most Asian countries, prospects for increasing rice lands are very limited, moreover their land-to-agricultural worker ratio is 0.27 , which is lowest in the world and 
is declining. Land to population ratios are also decreasing and most Asian countries must produce more rice on less land.

In this regard, hybrid rice technology is considered as one of the promising, practical, sustainable, and eco-friendly options to break the yield ceiling in rice (Virmani, 1994).

The decade of 1960s has been an eventful for rice research and development. The semidwarf rice varieties revolutionized the rice production worldwide. In the same period professor Yuan Long Ping acknowledged as "Father of Hybrid Rice" pioneered research on hybrid rice in China during 1964.

Strenuous efforts of Prof Yuan Long Ping and his associates resulted in development and identification of heterotic rice hybrids. Around 15-20 per cent higher yields of hybrid rice over best semi-dwarf inbred local varieties, is found in many countries (FAO, 2014).

Heterosis in rice is being exploited mainly through the utilization of male sterility system. Although research on male sterility in rice was first initiated in China in 1964, heterosis in rice was not successfully exploited until the discovery of wild abortive male sterile cytoplasm in the wild species Oryza rufipogon Griff. at Hainan Island in 1970. By 1973, China had the means to develop $F_{1}$ hybrids using three-line system of hybrid rice production, which involves a male sterile (A) line, a maintainer (B) line, and a restorer $(\mathrm{R})$ line.

The commercial exploitation of heterosis has been attained by the use of cytoplasmic genetic male sterility and fertility restoration systems. Identification of sterility maintainers and fertility restorers is ensured by estimating the pollen fertility and spikelet fertility percentages.

\section{Materials and Methods}

The experiment related to the identification of sterility maintainers and fertility restorers in rice was conducted at Agricultural Research Station, Gangavati, University of Agricultural Sciences, Raichur, which is situated in the Northern Dry Zone of Karnataka between $15^{\circ}-15^{\prime} 40^{\prime \prime}$ North latitude and $76^{\circ}-31^{\prime} 40^{\prime \prime}$ East longitude and at an altitude of $419 \mathrm{~m}$ above mean sea level. The experimental material for the present study, comprised of fifty pollen parents having diverse genetic backgrounds, five female lines and eighty-four experimental hybrids derived from crosses between the CMS lines and pollen parents. The material was collected from Indian Institute of Rice Research (IIRR), Hyderabad and ARS Gangavati, UAS Raichur. A total of one hundred and forty-three entries (five female lines, fifty pollen parents, eighty-four hybrids and four checks) were grown in an augmented block design with no replication. The plot was divided into four blocks and twenty-one hybrids and their respective female and male parents were sown adjacent to hybrid blocks. Four checks were repeated in each block.

Experimental hybrids were evaluated for pollen fertility and spikelet fertility and the observations recorded on pollen fertility and spikelet fertility were utilized as indices for the identification of sterility maintainers and fertility restorers of different cytoplasmic male sterile lines used in the study.

\section{Estimation of pollen fertility}

At the time of flowering, panicles from three randomly chosen plants were collected in each of the hybrids early in the morning just before blooming and are placed in petri plates under moist condition. Anthers of three randomly taken spikelets representing lower, middle and a top portion of the panicles were smeared in solution containing $1 \% \mathrm{I}_{2}$-KI 
(Iodine-Potassium Iodide) and are examined under foldscope. A foldscope is an optical microscope that can be assembled from simple components, including a sheet of paper and a lens. It was developed by Manu Prakash and designed to cost less than US \$1 to build. It provides magnification of $140 \mathrm{X}$.

The kit includes magnets that can be stuck onto the foldscope to attach it to a smartphone, allowing the user to take pictures of the magnification. The prepared slide is inserted into the paper microscope and the fertile/sterile pollens were counted and the pictures are taken with the help of smartphone.

The observation on pollen fertility/sterility was recorded by counting the number of fertile pollen grains and sterile pollen grains. The pollens were considered to be fertile if they were plumpy, round and deeply stained, while they were considered as sterile if they were shrunken, unstained and irregular in shape. The pollens were classified based on their shape, size and extent of staining as per the classification given below (Virmani et al., 1997; Chaudhary et al., 1981). Three microscopic fields were counted for each plant and pollen fertility was expressed in percentage. The pollen parent of the hybrid was classified into different categories viz., completely sterile, partially sterile, partially fertile and fully fertile (Virmani et al., 1997) (Table 1 and 2).

The numbers of fertile pollens and total pollens were used for calculating the pollen fertility percentage as under:

Pollen fertility $(\%)=\frac{\text { No. of fertile (stained) pollen grains }}{\text { Total no. of pollen grains }} \times 100$

Table.1 Categories of rice pollen and their features shown as follows

\begin{tabular}{|c|l|l|}
\hline Categories of pollen & Shape and staining behavior & Classification \\
\hline $\begin{array}{c}\text { Unstained withered } \\
\text { sterile (UWS) }\end{array}$ & Withered and undeveloped, unstained & Sterile \\
\hline $\begin{array}{c}\text { Unstained spherical } \\
\text { sterile (USS) }\end{array}$ & Spherical and smaller, unstained & Sterile \\
\hline $\begin{array}{c}\text { Stained round sterile } \\
\text { (SRS) }\end{array}$ & $\begin{array}{l}\text { Round and small, lightly or incompletely } \\
\text { stained, rough surface }\end{array}$ & Sterile \\
\hline $\begin{array}{c}\text { Stained round fertile } \\
\text { (SRF) }\end{array}$ & $\begin{array}{l}\text { Round and large, darkly stained, smooth } \\
\text { surface }\end{array}$ & Fertile \\
\hline
\end{tabular}

Table.2 Classification of pollen parents based on pollen fertility status of their test cross hybrids

\begin{tabular}{|l|c|}
\hline \multicolumn{1}{|c|}{ Class } & Pollen fertility (\%) \\
\hline Fully maintainer (FM) & $0-1$ \\
\hline Partial maintainer (PM) & $1.10-50$ \\
\hline Partial restorer (PR) & $50.10-80$ \\
\hline Fully restorer (FR) & $>80$ \\
\hline
\end{tabular}




\section{Estimation of spikelet fertility}

At the time of harvesting, five panicles including one from the main culm were harvested from randomly chosen five different plants in each of the hybrid. The number of filled spikelets and unfilled spikelets were counted, after threshing the panicles and the spikelet fertility was expressed in percentage as the number of filled spikelets to the total number of spikelets (filled spikelet and unfilled spikelet). Based on spikelet fertility, pollen parents of the experimental hybrids were classified into four classes (Virmani et al., 1997) as given in table 3.

Spikelet fertility percentage was calculated as under:

Spikelet fertility $(\%)=\frac{\text { Number of filled spikelets }}{\text { Total number of spikelets }} \times 100$

Table.3 Classification of pollen parent based on spikelet fertility percent of the corresponding hybrids

\begin{tabular}{|l|c|}
\hline \multicolumn{1}{|c|}{ Class } & $\begin{array}{c}\text { Spikelet fertility } \\
(\boldsymbol{\%})\end{array}$ \\
\hline Fully maintainer (FM) & 0 \\
\hline $\begin{array}{l}\text { Partial maintainer } \\
\text { (PM) }\end{array}$ & $0.10-50.00$ \\
\hline Partial restorer (PR) & $50.10-75.00$ \\
\hline Fully restorer (FR) & $>75$ \\
\hline
\end{tabular}

Identification of maintainers possessing recessive fertility restorer gene or genes and restorers with dominant fertility restorer genes or gene is the main step in exploitation of hybrid vigor, and is fundamental for the commercial exploitation of heterosis breeding programme using cytoplasmic male sterility (CMS) system (Rosamma and Vijayakumar, 2005; Sharma et al., 2012). Identification of restorers and maintainers was carried out by categorizing them based on observations recorded on pollen fertility and spikelet fertility percentage as per the classification given by Virmani et al., (1997) into four classes namely, fully maintainer, partial maintainer, partial restorer, and fully restorer.

\section{Results and Discussion}

Experimental materials for the identification of sterility maintainers and fertility restorers comprised of 84 test cross progenies derived from combinations involving 5 WA- CMS lines and 50 pollen parents. Identification of restorers and maintainers was carried out by categorizing them based on observations recorded on pollen fertility and spikelet fertility percentage as per the classification given by Virmani et al., (1997) into four classes namely, fully maintainer, partial maintainer, partial restorer, and fully restorer. Pollen fertility restoration pattern observed in experimental hybrids as observed under foldscope is depicted in Figure 1.

Results showed that, $\mathrm{F}_{1}$ hybrids produced by crossing CMS lines with selected rice genotypes behaved differently with regard to pollen and spikelet fertility and are presented in the Table 4. Among $84 \mathrm{~F}_{1}$ hybrids different levels of pollen and spikelet sterility/fertility were observed. Such variation in pollen fertility indicated the existence genetic variation in respect of these reproductive traits among the genotypes.

The pollen fertility ranged from 0.09 per cent to 90.5 per cent, and the range of spikelet fertility was from 0 per cent to 95.87 per cent. The highest and lowest percentages of pollen and spikelet fertility were found in 9A x SC5 and 7A x SC22 respectively. Similar results were also found by Islam et al., (2015). Out of $84 \mathrm{~F}_{1}$ hybrids having CMS lines with WA cytoplasm, 13 lines were completely fertile 
and 5 completely sterile. The remaining 66 hybrids expressed varying degrees of fertility (both pollen and spikelet). Forty-nine of them were partial maintainers and the remaining seventeen were partial restorers (based on spikelet fertility). The frequencies of fully maintainer, partial maintainer, partial restorer, and fully restorer male lines based on pollen fertility are 5.95, 59.50, 19.04, 15.47 per cent respectively, and based on spikelet fertility are 5.95, 58.32, 20.23, 15.47 per cent respectively, as illustrated in Table 5 (based on pollen fertility), Table 6 (based on spikelet fertility) and graphical representation of per cent frequency of restorers and maintainers based on pollen fertility and spikelet fertility is shown in Figure 2.

In the present study, among $84 \mathrm{~F}_{1}$ hybrids raised through crossing 50 pollen parents with 5 CMS lines, the frequency of maintainers which was found to be 64.27 per cent $(5.95 \%$ for complete maintainers and $58.32 \%$ for partial maintainers) was higher than the frequency of restorers which accounts for 35.7 per cent ( $20.23 \%$ for partial restorer and 15.47 for complete restorer). Akhter et al., (2008) reported similar results where frequency of maintainers (13\% complete maintainers and $41 \%$ partial maintainers) was higher than that of the restorers (9\% complete restorers and $37 \%$ partial restorers). The lines identified as effective maintainers could be further backcrossed with their respective $F_{1}$ 's to look for completely sterile backcross progenies so that, these can be developed as new CMS lines which in turn can be used as female parent to develop high yielding rice hybrids. The lines identified as complete restorers could be utilized in the heterosis breeding (hybrid development programme) as male parents after testing their combining ability and heterosis.

There were instances, in which classification of tester based on the pollen fertility did not correlate with the classification based on the fertility of spikelet. For example, LR31 crossed with 6A was classified as partial restorer based on pollen fertility, and as partial maintainer based on spikelet fertility. SC4 behaved as partial maintainer when crossed with 7A according to pollen fertility percentage whereas, it is categorized under partial restorer according to spikelet fertility percentage. The cross 7A/TJ6 was classified as partial restorer based on pollen fertility percentage, and it was classified as fully restorer based on spikelet fertility percentage. Such lack of correlation between pollen fertility percentage, and percentage of spikelet fertility was reported by Murugan and Ganesan (2006); Riaz et al., (2017); Das et al., (2013); Joshi (2003).

In in majority of cases, it was found that pollen fertility was higher than spikelet fertility, but in some crosses like 10A/SC48, 9A/SC43, 8A/SC21, 7A/SC56, 6A/SC5 etc. spikelet fertility was higher than pollen fertility. This type of differential reaction of pollen parents may be attributed to the ability of single fertile pollen to fertilize a spikelet. Therefore, even low number of fertile pollens counted in any genotype in the study, can give higher seed set (Joshi et al., 2003). Some of the factors like, difference in panicle exsertion percentage, higher angle of panicle exsertion and some percent of outcrossing alone or in combination have contributed for the higher spikelet fertility than pollen fertility. It suggests that, the pollen fertility in some cases, is independent of spikelet fertility, though in majority of cases there was positive correlation between pollen fertility and spikelet fertility percentage. Veeresha (2012) in his study found that some of the crosses like IR-58025A x Abhilash, IR-58025A x NP3-144, IR-58025A x BD-51 etc. recorded higher spikelet fertility than pollen fertility. In a study conducted by Kumar (2018) majority of the crosses were in line with the results obtained in the present study. 
In the present investigation it was observed that, there was differential fertility/sterility reaction of the same genotype (male) when crossed with different female parents i.e. same genotype behaved as fully maintainer when crossed with one female parent, whereas on crossing with another female parent it behaved as partial maintainer or same genotype was found to be partial maintainer for one CMS background while, it was fully restorer for another CMS background or same male genotype behaved as partial maintainer when crossed with one CMS line whereas, it behaved as partial restorer when crossed with another CMS line (as depicted in Table 7.

For example, SC22 behaved as fully maintainer when crossed with $7 \mathrm{~A}$ and $9 \mathrm{~A}$ CMS lines, while it behaved as partial maintainer when crossed with $8 \mathrm{~A}$ and $10 \mathrm{~A}$ female lines. SC48 behaved as fully maintainer when crossed with $9 \mathrm{~A}$ whereas, it behaved as partial maintainer when crossed with 10A. LR11 when crossed with 8A behaved as partial maintainer while, on crossing with $10 \mathrm{~A}$ it behaved as fully restorer. The pollen parent TJ1 was found to be partial maintainer for 7A and 10A CMS lines and fully restorer for 6A CMS line.

TJ18 male parent behaved as partial maintainer when crossed with 6A CMS line whereas, it behaved as fully restorer when crossed with 10A. Male line SC43 was partial maintainer for 9A CMS line, and it was partial restorer for 10A CMS line. SC13 was found to be partial maintainer for $9 \mathrm{~A}$ and $10 \mathrm{~A}$ CMS lines and it was partial restorer for $6 \mathrm{~A}$ CMS background. The genotype LR31 behaved as partial maintainer for $6 \mathrm{~A}$ and $7 \mathrm{~A}$ CMS lines whereas, it behaved as partial restorer for 10A CMS background. SC21 was found to be partial maintainer when crossed with 8A CMS line and it was partial restorer when crossed with 7A CMS line. The pollen parent SC56 behaved as partial maintainer when crossed with 7A and 10A CMS background while, it behaved as partial restorer for 6A, 8A, and 9A CMS lines. The genotype SC5 was found to be partial restorer for 6A and 7A CMS lines, whereas, it was found to be fully restorer for $9 \mathrm{~A}$ and $10 \mathrm{~A}$ CMS lines.

Such differential fertility restoring ability of same genotype (male parent) on crossing with different CMS backgrounds is also reported by many other researchers like, Yogesha and Mahadevappa (1994); Hemareddy et al., (2000); Gannamani (2001); Sao (2002); Bisne and Motiramani (2005); Hariprasanna et al., (2005); Murugan and Ganesan (2006); Sabar et al., (2007); Salgotra et al., (2007); Jayasudha and Sharma (2010); Umadevi et al., (2010); Krishnalatha and Sharma (2012); Das et al., (2013); Kumar et al., (2015).

These variations in behavior of some genotypes for fertility restoration could be due to, differential nuclear cytoplasmic interactions between the pollen parents (tester) and female parents (CMS line). It may be because of the different fertility restoring genes, or variations in their penetrance and expressivity of parental genotypes. It could be due to presence of modifier genes present in the male parent (Ganesan and Rangaswamy, 1998) or due to the influence of the genetic background of the female parent or the CMS line (Hossain et al., 2010) with that of the pollen parent.

If the numbers of sterility genes are in excess, then they may act as inhibitors of fertility restoration in $F_{1}$ hybrids. Some of the established restorers may show incomplete fertility restoration of WA type CMS lines, which is because of the presence of inhibitory genes (Govinda and Virmani, 1988) or hybrid sterility genes in the female parents (CMS lines). 
Table.4 Pollen and spikelet fertility and fertility restoration reaction of test crosses involving five CMS and 50 pollen parents

\begin{tabular}{|c|c|c|c|c|}
\hline Sl. No. & Crosses/hybrids & $\begin{array}{c}\text { Pollen fertility } \\
(\%)\end{array}$ & $\begin{array}{c}\text { Spikelet } \\
\text { fertility (\%) }\end{array}$ & $\begin{array}{c}\text { Designation of pollen } \\
\text { parent based on spikelet } \\
\text { fertility }\end{array}$ \\
\hline 1 & 7A/SC22 & 0.09 & 0.00 & FM \\
\hline 2 & 7A/SC49 & 0.10 & 0.00 & FM \\
\hline 3 & 9A/SC48 & 0.19 & 0.00 & FM \\
\hline 4 & 9A/SC22 & 0.50 & 0.00 & FM \\
\hline 5 & $8 \mathrm{~A} / \mathrm{SC} 49$ & 0.77 & 0.00 & FM \\
\hline 6 & 9A/LR32 & 1.50 & 6.06 & PM \\
\hline 7 & 8A/LR11 & 10.30 & 6.16 & PM \\
\hline 8 & 6A/SC17 & 2.40 & 7.50 & PM \\
\hline 9 & $8 \mathrm{~A} / \mathrm{SC} 22$ & 16.50 & 7.59 & PM \\
\hline 10 & 10A/TJ36 & 2.60 & 8.21 & PM \\
\hline 11 & 7A/SC45 & 16.60 & 8.84 & PM \\
\hline 12 & 10A/LR24 & 12.53 & 9.62 & PM \\
\hline 13 & 10A/SC22 & 2.60 & 10.03 & PM \\
\hline 14 & 7A/TJ1 & 16.10 & 10.43 & PM \\
\hline 15 & 6A/TJ18 & 14.90 & 11.81 & PM \\
\hline 16 & 10A/SC48 & 8.30 & 13.35 & PM \\
\hline 17 & 6A/LR6 & 18.60 & 13.49 & PM \\
\hline 18 & 9A/SC43 & 11.50 & 14.01 & PM \\
\hline 19 & 6A/LR23 & 15.50 & 14.35 & PM \\
\hline 20 & 6A/TJ14 & 22.30 & 14.55 & PM \\
\hline 21 & 8A/SC60 & 10.60 & 16.23 & PM \\
\hline 22 & 7A/LR32 & 13.19 & 17.27 & PM \\
\hline 23 & 6A/LR22 & 19.10 & 17.73 & PM \\
\hline 24 & 8A/LR39 & 22.60 & 18.19 & PM \\
\hline 25 & 7A/SC61 & 22.40 & 18.43 & PM \\
\hline 26 & 6A/TJ17 & 10.70 & 18.48 & PM \\
\hline 27 & $10 \mathrm{~A} / \mathrm{SC} 21$ & 32.20 & 20.24 & PM \\
\hline 28 & 10A/TJ1 & 13.80 & 22.34 & PM \\
\hline 29 & 9A/TJ24 & 14.40 & 22.71 & PM \\
\hline 30 & 9A/LR10 & 25.90 & 22.94 & PM \\
\hline 31 & 9A/SC13 & 28.10 & 25.37 & PM \\
\hline 32 & 6A/SC54 & 28.47 & 25.16 & PM \\
\hline 33 & 10A/SC45 & 22.60 & 26.89 & PM \\
\hline 34 & 10A/TJ22 & 20.60 & 27.20 & PM \\
\hline 35 & 8A/LR33 & 24.60 & 27.58 & PM \\
\hline 36 & $10 \mathrm{~A} / \mathrm{SC} 13$ & 30.60 & 27.61 & PM \\
\hline
\end{tabular}




\begin{tabular}{|c|c|c|c|c|}
\hline 37 & 7A/LR14 & 27.44 & 29.17 & PM \\
\hline 38 & 10A/LR48 & 33.40 & 30.47 & PM \\
\hline 39 & 9A/LR20 & 33.88 & 30.63 & PM \\
\hline 40 & 6A/SC24 & 25.60 & 30.86 & PM \\
\hline 41 & 9A/TJ17 & 34.90 & 31.03 & PM \\
\hline 42 & 10A/TJ17 & 35.20 & 31.38 & PM \\
\hline 43 & 6A/LR32 & 21.27 & 31.80 & PM \\
\hline 44 & 7A/LR31 & 30.80 & 32.04 & PM \\
\hline 45 & $8 \mathrm{~A} / \mathrm{SC} 29$ & 32.30 & 37.32 & PM \\
\hline 46 & 9A/TJ14 & 33.60 & 40.31 & PM \\
\hline 47 & 8A/LR22 & 38.60 & 40.65 & PM \\
\hline 48 & 10A/TJ16 & 48.70 & 41.57 & PM \\
\hline 49 & 10A/TJ14 & 47.30 & 42.19 & PM \\
\hline 50 & 10A/SC56 & 48.80 & 44.33 & PM \\
\hline 51 & 8A/SC21 & 43.60 & 45.14 & PM \\
\hline 52 & 6A/LR31 & 53.40 & 47.16 & PM \\
\hline 53 & 8A/SC45 & 45.20 & 48.74 & PM \\
\hline 54 & 7A/SC56 & 41.70 & 48.99 & $\mathrm{PM}$ \\
\hline 55 & $6 \mathrm{~A} / \mathrm{SC} 5$ & 51.40 & 53.00 & PR \\
\hline 56 & 10A/LR31 & 55.80 & 51.23 & PR \\
\hline 57 & 9A/SC46 & 60.50 & 51.76 & PR \\
\hline 58 & 6A/SC56 & 57.30 & 52.49 & PR \\
\hline 59 & 9A/SC56 & 58.60 & 54.10 & PR \\
\hline 60 & 7A/SC4 & 49.60 & 55.21 & PR \\
\hline 61 & 7A/SC47 & 53.90 & 65.00 & PR \\
\hline 62 & 7A/SC5 & 52.60 & 65.59 & PR \\
\hline 63 & 6A/TJ16 & 55.70 & 66.39 & PR \\
\hline 64 & 8A/LR54 & 53.70 & 66.59 & PR \\
\hline 65 & $10 \mathrm{~A} / \mathrm{SC} 43$ & 59.50 & 68.22 & PR \\
\hline 66 & 6A/SC13 & 59.70 & 69.31 & PR \\
\hline 67 & 6A/TJ11 & 62.30 & 71.60 & PR \\
\hline 68 & 10A/SC4 & 78.10 & 72.59 & PR \\
\hline 69 & 8A/SC56 & 71.70 & 73.32 & PR \\
\hline 70 & 10A/TJ31 & 79.60 & 74.23 & PR \\
\hline 71 & 7A/SC29 & 82.40 & 74.88 & PR \\
\hline 72 & 10A/LR11 & 81.30 & 75.70 & FR \\
\hline 73 & 6A/SC30 & 81.80 & 76.28 & FR \\
\hline 74 & 10A/TJ27 & 80.20 & 76.81 & FR \\
\hline 75 & 10A/SC53 & 83.80 & 78.51 & FR \\
\hline 76 & 7A/SC31 & 86.90 & 79.86 & FR \\
\hline
\end{tabular}




\begin{tabular}{|l|c|c|c|c|}
\hline $\mathbf{7 7}$ & 7A/TJ6 & 75.40 & 83.43 & FR \\
\hline $\mathbf{7 8}$ & 10A/SC31 & 82.90 & 84.19 & FR \\
\hline $\mathbf{7 9}$ & 8A/LR53 & 87.20 & 84.25 & FR \\
\hline $\mathbf{8 0}$ & 6A/TJ1 & 87.20 & 84.36 & FR \\
\hline $\mathbf{8 1}$ & 10A/TJ18 & 87.10 & 86.00 & FR \\
\hline $\mathbf{8 2}$ & 6A/SC9 & 91.10 & 90.28 & FR \\
\hline $\mathbf{8 3}$ & 10A/SC5 & 89.50 & 91.57 & FR \\
\hline $\mathbf{8 4}$ & 9A/SC5 & 90.50 & 95.87 & FR \\
\hline & Mean & 41.07 & 40.08 & \\
\hline & Minimum & 0.09 & 0.00 & \\
\hline & Maximum & 90.50 & 95.87 & \\
\hline
\end{tabular}

Table.5 Frequency of restorers and maintainers based on pollen fertility

\begin{tabular}{|c|c|c|c|c|c|c|c|c|}
\hline \multirow{2}{*}{ CMS lines } & \multicolumn{7}{|c|}{ Classification based on pollen fertility } \\
\hline & FM & \% & PM & \% & PR & \% & FR & \% \\
\hline $\mathbf{6 A}$ & 0 & 0 & 11 & 13.09 & 5 & 5.95 & 3 & 3.57 \\
\hline $\mathbf{7 A}$ & 2 & 2.38 & 8 & 9.52 & 3 & 3.57 & 2 & 2.38 \\
\hline $\mathbf{8 A}$ & 1 & 1.19 & 9 & 10.71 & 2 & 2.38 & 1 & 1.19 \\
\hline $\mathbf{9 A}$ & 2 & 2.38 & 8 & 9.52 & 2 & 2.38 & 1 & 1.19 \\
\hline $\mathbf{1 0 A}$ & 0 & 0 & 14 & 16.66 & 4 & 4.76 & 6 & 7.14 \\
\hline Total (\%) & 5 & 5.95 & 50 & 59.5 & 16 & 19.04 & 13 & 15.47 \\
\hline
\end{tabular}

Table.6 Frequency of restorers and maintainers based on spikelet fertility

\begin{tabular}{|c|c|c|c|c|c|c|c|c|}
\hline \multirow{2}{*}{ CMS lines } & \multicolumn{8}{|c|}{ Classification based on spikelet fertility } \\
\cline { 2 - 10 } & FM & \% & PM & \% & PR & \% & FR & \% \\
\hline $\mathbf{6 A}$ & 0 & 0 & 11 & 13.09 & 5 & 5.95 & 3 & 3.57 \\
\hline $\mathbf{7 A}$ & 2 & 2.38 & 7 & 8.33 & 4 & 4.76 & 2 & 2.38 \\
\hline $\mathbf{8 A}$ & 1 & 1.19 & 9 & 10.71 & 2 & 2.38 & 1 & 1.19 \\
\hline $\mathbf{9 A}$ & 2 & 2.38 & 8 & 9.52 & 2 & 2.38 & 1 & 1.19 \\
\hline $\mathbf{1 0 A}$ & 0 & 0 & 14 & 16.67 & 4 & 4.76 & 6 & 7.14 \\
\hline Total (\%) & 5 & 5.95 & 49 & 58.32 & 17 & 20.23 & 13 & 15.47 \\
\hline
\end{tabular}


Table.7 Differential fertility/sterility reaction of the same genotype (male) when crossed with different female parents

\begin{tabular}{|c|c|c|c|}
\hline Sl. No. & Male parent & Female parent & $\begin{array}{l}\text { Differential fertility/sterility } \\
\text { reaction }\end{array}$ \\
\hline \multirow[t]{2}{*}{1} & SC 22 & $7 \mathrm{~A}, 9 \mathrm{~A}$ & Fully Maintainer \\
\hline & & $8 \mathrm{~A}, 10 \mathrm{~A}$ & Partial Maintainer \\
\hline \multirow[t]{2}{*}{2} & SC 48 & $9 \mathrm{~A}$ & Fully Maintainer \\
\hline & & $10 \mathrm{~A}$ & Partial Maintainer \\
\hline \multirow[t]{2}{*}{3} & LR 11 & $8 \mathrm{~A}$ & Partial Maintainer \\
\hline & & $10 \mathrm{~A}$ & Fully Restorer \\
\hline \multirow[t]{2}{*}{4} & $\mathrm{TJ} 1$ & $7 \mathrm{~A}, 10 \mathrm{~A}$ & Partial Maintainer \\
\hline & & $6 \mathrm{~A}$ & Fully Restorer \\
\hline \multirow[t]{2}{*}{5} & TJ 18 & $6 \mathrm{~A}$ & Partial Maintainer \\
\hline & & $10 \mathrm{~A}$ & Fully Restorer \\
\hline \multirow[t]{2}{*}{6} & SC 43 & $9 \mathrm{~A}$ & Partial Maintainer \\
\hline & & $10 \mathrm{~A}$ & Partial Restorer \\
\hline \multirow[t]{2}{*}{7} & SC 13 & $9 \mathrm{~A}, 10 \mathrm{~A}$ & Partial Maintainer \\
\hline & & $6 \mathrm{~A}$ & Partial Restorer \\
\hline \multirow[t]{2}{*}{8} & LR 31 & $6 \mathrm{~A}, 7 \mathrm{~A}$ & Partial Maintainer \\
\hline & & $10 \mathrm{~A}$ & Partial Restorer \\
\hline \multirow[t]{2}{*}{9} & SC 21 & $8 \mathrm{~A}$ & Partial Maintainer \\
\hline & & $7 \mathrm{~A}$ & Partial Restorer \\
\hline \multirow[t]{2}{*}{10} & SC 56 & $7 \mathrm{~A}, 10 \mathrm{~A}$ & Partial Maintainer \\
\hline & & $6 \mathrm{~A}, 8 \mathrm{~A}, 9 \mathrm{~A}$ & Partial Restorer \\
\hline \multirow[t]{2}{*}{11} & SC 5 & $6 \mathrm{~A}, 7 \mathrm{~A}$ & Partial Restorer \\
\hline & & $9 \mathrm{~A}, 10 \mathrm{~A}$ & Fully Restorer \\
\hline
\end{tabular}




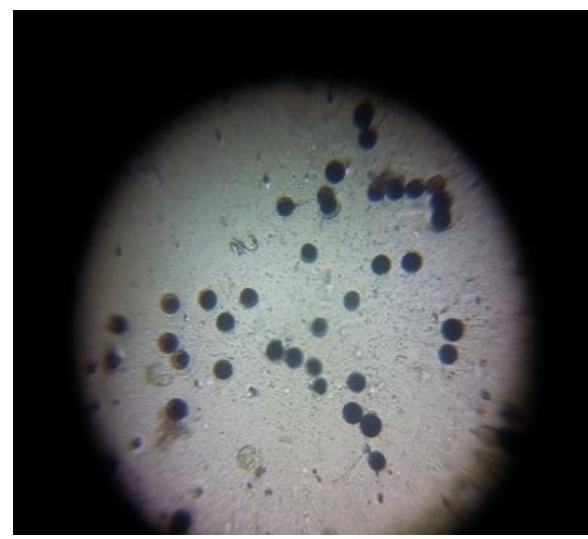

Complete restorer

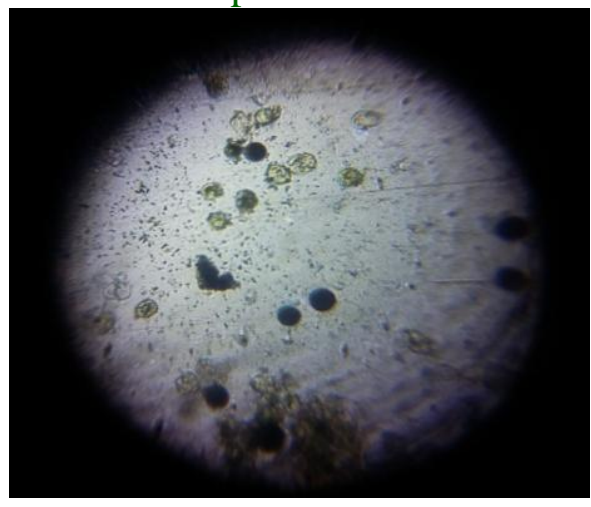

Partial maintainer

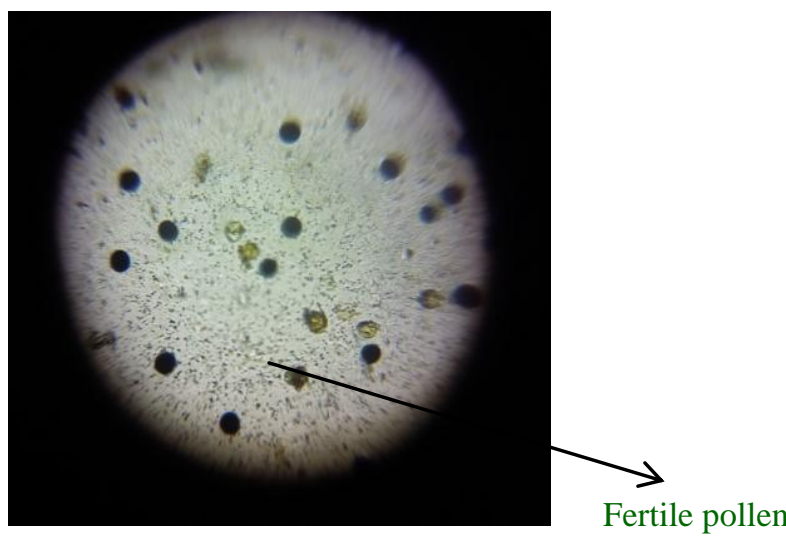

Partial restorer

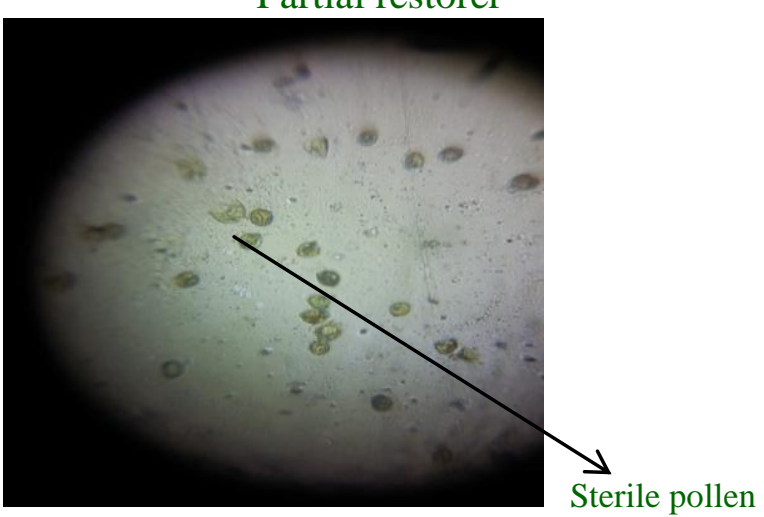

Complete maintainer

Figure.1 Pollen fertility restoration pattern observed in experimental hybrid under foldscope

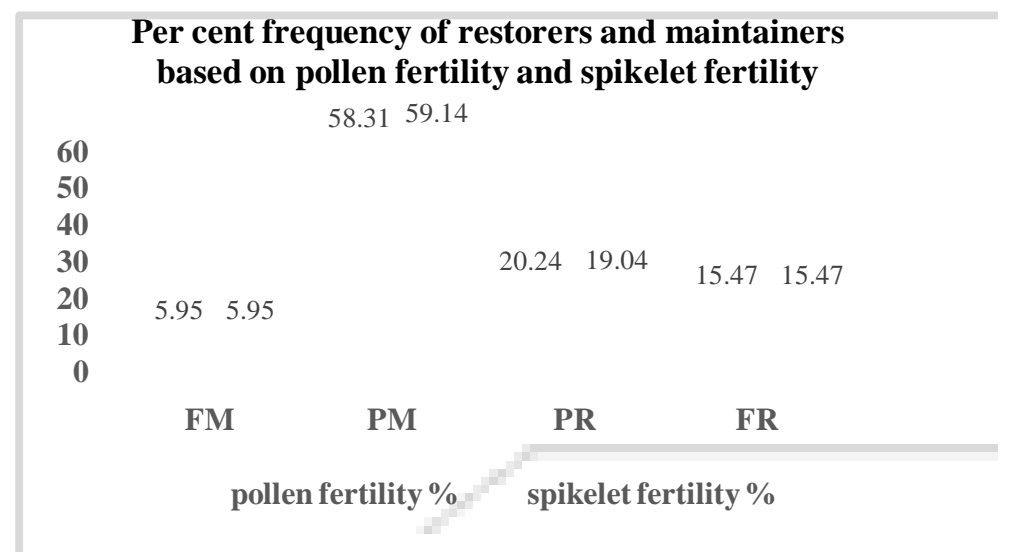

Figure.2 Per cent frequency of restorers and maintainers based on pollen fertility and spikelet fertility

According to Wilson (1998) this differential fertility reaction of same genotype is due to variation in the number of sterility/fertility genes or complementary or additive interaction of fertility genes with restorer genes or effectiveness among CMS lines. Pradhan and Jachuck (1998) suggested that the partial restoration or partial maintenance in some cases must be due to heterozygous condition of fertility restoring genes. 
Identification of sterility maintainers and fertility restorers is a crucial step in development of hybrids in case of rice. Hybrids produced by crossing CMS lines with selected rice genotypes behaved differently both with regard to pollen and spikelet fertility in the study. Among $84 \mathrm{~F}_{1}$ hybrids 13 hybrids were completely fertile and 5 were completely sterile. The remaining 66 hybrids expressed varying degrees of fertility (both pollen and spikelet). Forty-nine of them were partial maintainers and the remaining seventeen were partial restorers (based on spikelet fertility).

The identified promising complete restorers and complete maintainers can be further exploited in heterosis breeding. The identified complete restorer genotypes can be crossed with promising male sterile line to develop high yielding hybrid. Complete sterile crosses identified in the study can be used for developing new CMS lines through backcrossing them with respective $F_{1} s$ which in turn can be used as female lines in hybrid development.

\section{References}

Akhter, M., Zahid, M. A., Sabar, M. and Ahmad, M., 2008, Identification of restorers and maintainers for the development of rice hybrids. JAPS, 18(1): 39-41.

Bisne, R. and Motiramani, N. K., 2005, Identification of maintainers and restorers using WA source cytoplasmic male sterile lines in rice. Int. Rice Res., 30(1): 14-15.

Chaudhary, R. C., Virmani, S. S. and Khush, G. S., 1981, Patterns of pollen abortion in some cytoplasmic-genetic male sterile lines of rice. Oryza, 18: 140-142.

Das, P., Mukherjee, B., Santra, C, K., Mukhopadhyay, S., Dasgupta, T., 2013, Evaluation of genotypes for fertility restoring and maintaining behaviors in rice (Oryza sativa L.). IJSTR, 2: 228-232.

Food and Agriculture Organization (FAO), 2014, www.fao.org.in.
Ganesan, K. N. and Rangaswamy, M., 1998, Combining ability studies in rice hybrids involving wild abortive (WA) and Oryza perennis sources of CMS lines. Oryza, 35(2): 113-116.

Gannamani, N. 2001, Study of heterosis and combining ability by utilizing cytoplasmic genetic male sterility and fertility restoration system in rice. M.Sc. (Agri.) thesis, IGAU, Raipur, India.

Govinda Raj, K. and Virmani, S. S., 1988, Genetics of fertility restoration of WA type cytoplasmic male sterility in rice. Crop Sci., 28: 787-792.

Hariprasanna, K., Zaman, F. U. and Singh, A. K., 2005. Identification of versatile fertility restorer genotypes for diverse CMS lines of rice. Oryza, 42: 20-26.

Hemareddy, H. B., Lohitswa, H. C., Patil, R. S., Manjunath, A., Mahadevappa, M. and Kulkarni, R. S., 2000, Differential fertility restoration behaviour of genotypes of WA, Oryza perennis and MS 577 A cyto-sterile system of rice. Oryza, 37(1): 26-28.

Hossain, S., Singh A. K., and Zaman, F., 2010, Genetics of fertility restoration of 'WA'based cytoplasmic male sterility system in rice (Oryza sativa L.) using Indica/Japonica derivative restorers. Sci. Asia, 36: 94-99.

Islam, A., Mian, M. A. K., Rasul, G., Bashar, K. and Johora, F. T., 2015, Development of component lines (CMS, maintainer and restorer lines) and their maintenance using diversed cytosources of rice. J. Rice Res., 3(3): 140-145.

Jayasudha, S. and Sharma, D., 2010, Identification of restorers and maintainers for CMS lines of rice (Oryza sativa L.) under shallow lowland condition. Electron. J. Pl. Breed., 1(3): 311-314.

Joshi, B. K., 2003, Heterosis in $\mathrm{F}_{1}$ rice hybrids. $J$. Inst. Agric. Anim. Sci., 24: 29-36.

Joshi, B. K., Subedi, L. P., Gurung. S. B. and Sharma, R. C., 2003, Evaluation of cultivars and land races of rice (Oryza sativa L.) for restoring and maintaining wild abortive cytoplasm. Him. J. Sci., 1(2): 87-91.

Krishnalatha, S. and Sharma, D., 2012, Identification of maintainers and restorers 
for WA and Kalinga sources of CMS lines in rice (Oryza sativa L.). Electron. J. Pl. Breed., 3(4): 949-951.

Kumar, P., 2018, Molecular evaluation of sterility maintainers and fertility restorers for wild abortive rice cytoplasm. M. Sc. (Agri.) thesis, Dr. Rajendra Prasad Central Agricultural University, Samastipur.

Kumar, P., Sharma, V. K. and Prasad, B. D., 2015, Characterization of maintainer and restorer lines for wild abortive cytoplasmic male sterility in indica rice (Oryza sativa L.) using pollen fertility and microsatellite (SSR) markers. Australian J. Crop Sci., 9(5):3 84-393.

Murugan, S. and Ganesan, J., 2006, Pollen and spikelet fertility analysis in rice crosses involving WA cytosteriles. Int. J. Agric. Sci., 2: 315-316.

Pradhan, S. B. and Jachuck, P. J., 1998, CMS lines in the background of four different cytoplasmic sources in rice. Int. Rice Res. Notes, 23: 6.

Riaz, M., Iqbal, M., Akhter, M., Latif, T., Khan, A. R. and Bibi, T., 2017, Assessment of genetic combinations for hybrid rice in the germplasm of Pakistan. Asian J. Agric. Res., 4(3): 1-8.

Rosamma, C. A. and Vijayakumar N. K., 2005, Maintainers and restorers for CMS lines of rice. J. Trop. Agric., 43(1-2): 75-77.

Sabar, M., Akhter, M., Faiaz, A. F., Syed, S. A. and Musthtaq, A., 2007, Identification of restorers and maintainers for developing hybrid rice. J. Agric. Res., 45(1): 1-6.

Salgotra, R. K., Gupta, B. B. and Bijral, J. S., 2007, Identification and restorers and maintainers for cytoplasmic-genic male sterile lines of basmati rice. SKUAST J.
Res., 2: 249-252.

Sao, A., 2002, Studies on combining ability and heterosis in $F_{1}$ rice hybrids using cytoplasmic male sterile lines. M. Sc. (Agri.) thesis, Indira Gandhi Agricultural University, Raipur, India.

Sharma, S. K., Singh, S. K., Nandan, R. and Kumar, M., 2012, Identification of restorers and maintainers for CMS lines of rice (Oryza sativa L.). Indian J. Pl. Genet. Resour., 2: 186-188.

Umadevi, M., Veerabadhiran, P., Manonmani, S. and Shanmugasundaram, P., 2010, Identification of potential maintainers and restorers using cytoplasmic male sterile lines in rice. Electron. J. Pl. Breed., 1(4): 948-952.

Veeresha, 2012, Identification of new restorers, maintainers and development of hybrid rice for the rainfed upland condition. M. Sc. (Agri.) thesis, UAS Dharwad.

Virmani, S. S., 1994, Prospects of hybrid rice I n the tropics and subtropics. Hybrid rice technology: New developments and future prospects. IRRI, Manila, Philippines, pp: 719.

Virmani, S. S., Virakamath, B. C., Laral, C. L., Toledo, R.S., Lopez, M. T. and Manalo, J. O., 1997, Hybrid rice breeding manual. IRRI, Philippines, pp: 151.

Wilson, J. A., 1998, Genetics of fertility restoration of male sterility. Euphytica, 6: 13-33.

Yogesha, H. S. and Mahadevappa, M., 1994, Restorers and maintainers for MS 577A and wild abortive (WA) cytoplasmic male sterile system. Int. Rice Res. Newsl., 19(2): 6.

\section{How to cite this article:}

Vanitha, Jayateertha R. Diwan, D. Shreedhara, Vikas V. Kulkarni, K. Mahantashivayogayya and Vijaykumar N. Ghante. 2020. Identification of Maintainer and Restorer Lines for WA Cytoplasmic Male Sterility in Rice Using Pollen Fertility and Spikelet Fertility. Int.J.Curr.Microbiol.App.Sci. 9(04): 3125-3137. doi: https://doi.org/10.20546/ijcmas.2020.904.365 